\title{
A IMPORTÂNCIA DA AFETIVIDADE NO PROCESSO DE DESENVOLVIMENTO DA EDUCAÇÃO INFANTIL
}

\section{THE IMPORTANCE OF AFFECTIVITY IN THE PROCESS OF DEVELOPMENT OF EARLY CHILDHOOD EDUCATION}

\author{
Rosana Guimarães Lôbo Sahium ${ }^{1}$ \\ Lhuria Maryane Alves Gomes Braga ${ }^{2}$ \\ Nívia Teixeira Braga Araújo ${ }^{3}$ \\ https://doi.org/10.29327/216986.1.1-4
}

RESUMO: Este artigo apresenta o tema da afetividade na educação infantil, cujo objetivo foi identificar e analisar a importância da afetividade no processo de desenvolvimento da Educação Infantil. Para alcançar os objetivos propostos foram realizadas pesquisas bibliográficas e de campo. Ambas buscaram verificar a problemática e as hipóteses como verdadeiras ou falsas. Nas considerações finais foi verificado que as hipóteses deste estudo são verdadeiras, pois foi notado que apesar da necessidade de se desenvolver emocionalmente ainda há educadores que permeiam sua prática baseada no tradicionalismo, onde o que vale são os conteúdos e não dão a devida importância para a afetividade da criança pelo fato de não reconhecerem as vantagens promovidas pelo afeto.

Palavras-chave: Desenvolvimento. Afeto. Educação. Infantil.

\footnotetext{
${ }^{1}$ Mestra em Educação pela PUC - GO; Especilaista em Psicopedagogia pela UniEvangélica - Anápolis; Graduada em Pedagogia e Letrass pela Faculdade de Filosofia Bernardo Sayão - AEE. http://lattes.cnpq.br/9989573149199665 niviateixeiravz@hotmail.com

${ }^{2}$ Licenciada do curso de Pedagogia EAD da Faculdade do Noroeste de Minas - FINOM. E-mail: lhuriamaryane8@gmail.com

${ }^{3}$ Licenciada do curso de Pedagogia EAD da Faculdade do Noroeste de Minas - FINOM. E-mail: niviateixeiravz@hot.com E-mail: lhuriamaryane8@gmail.com
}

Educação In Loco, v.01, n. 01, jan.-jun. 2020 - ISSN 2675-4304 
ABSTRACT: The names aligned to the right one below the other, identifying the institution of belonging of the authors. The abstract should be the same one submitted by the maximum proposal of 10 lines, in a single paragraph. The abstract should contain, in a synthetic way, the main points addressed in the study, referring to the introduction, justification, problem, hypothesis, objective, methodology, social relevance and academic relevance.

Keywords: Development. Affection. Education. Children's.

\section{Introdução}

Este artigo é um estudo bibliográfico e de campo cujo tema é a importância da afetividade na Educação Infantil no processo de desenvolvimento das crianças A afetividade é uma temática que está ligada ao desenvolvimento global da criança.

Um dos primeiros teóricos a falar sobre a educação emocional foi Wallon no ano de 1879. Este teórico inovou o cenário educativo ao enfatizar que há três dimensões para o desenvolvimento efetivo: cognitiva, motora e afetiva. Dimensões estas que estão interligadas, se uma não for bem trabalhada, acabará abalando a outra, de maneira que o desempenho do ser humano não será efetivo. (SNYDERS, 1979).

$\mathrm{Na}$ verdade, de acordo com Almeida (2012), Wallon sobrepõe a afetividade sobre as demais dimensões citadas, pois se o emocional estiver abalado o desenvolvimento será mínimo se comparado às potencialidades que o indivíduo possui para se desenvolver.

Alguns estudiosos como Piaget (1986) e Vygotsky (1984, 2003), já ressaltavam a importância do afeto no processo do desenvolvimento humano, porém foi Wallon (2006) com a teoria psicogenética, a ressaltar que o ser humano nasce trazendo consigo conhecimentos biológicos que serão modificados pelo meio no qual 
está inserido. Wallon (2006) defende o desenvolvimento humano centrado em três dimensões, são elas: "paixão, sentimento e emoção".

De acordo com Tardif (2002) a afetividade é uma via de mão dupla que começa no momento do planejamento do professor e que se estende na sala de aula com a execução de suas ações e respostas de seus alunos. Nesta perspectiva, complementa Almeida (2012) que, o educador tem uma função fundamental no processo de ensino aprendizagem da criança, além de promover a intermediação entre aluno e o conhecimento, cabe a ele conhecer os anseios, as emoções, angústias e desejos de seus educandos.

O objetivo geral deste estudo foi identificar e analisar a importância da afetividade no processo de desenvolvimento da Educação Infantil. Os objetivos específicos foram: reconhecer os principais teóricos que falam sobre a importância do afeto como objeto de aprendizagem; identificar como os professores desenvolvem na prática a afetividade e se esta é reconhecida por eles como um bem necessário ao desenvolvimento dos alunos; relacionar teoria e prática voltada para práticas efetivas do afeto.

\section{Este trabalho buscou responder a seguinte questão:}

Por que apesar da necessidade de se desenvolver emocionalmente, ainda há educadores que norteiam sua prática baseada num ensino conteudista e não dão a devida importância para a afetividade da criança?

Para responder a problemática estabelecida foram organizadas as seguintes hipóteses:

- Alguns educadores não reconhecem a importância estrutural da aprendizagem pelo afeto.

- O ensino infantil prioriza a dimensão cognitiva em detrimento da dimensão afetiva.

- Falta de conhecimento da teoria psicogenética de Wallon (1989), propõe métodos arcaicos de ensino aprendizagem tendo como foco apenas o desenvolvimento cognitivo e motor.

Para melhor entender a temática exposta, este trabalho é desenvolvido de modo teórico e prático. Aborda questões como a importância da afetividade no processo de desenvolvimento da 
Educação Infantil, mediado pelo reconhecimento dos principais teóricos que falam sobre a importância do afeto, bem como a relação prática e teórica vivenciada por uma professora de uma escola infantil da cidade de Vazante em Minas Gerais.

Ao verificar a importância da afetividade na educação infantil, este artigo buscou conhecer como é vivenciada a teoria psicogenética de Wallon em uma escola municipal infantil da cidade de Vazante, o mesmo não é um trabalho de julgamento da prática educativa, mas sim um trabalho científico que será capaz de verificar como alunos e professores vivenciam a afetividade no processo ensino aprendizagem. Logo, se constitui numa ferramenta de análise para educadores, supervisores, psicopedagogos, pedagogos e demais pessoas que lidam ou interessam-se pelo desenvolvimento afetivo na educação infantil.

\section{Afetividade: gênese e importância}

A afetividade ganhou impulso com os estudos de Wallon, ele teve seus preceitos aliados aos de Piaget e Vygotsky que também já falavam da interação entre sujeito e objeto mediado pelas interações humanas. A partir dos descritos destes dois estudiosos, Wallon (1989), começa a dar ênfase às suas análises de maneira a colocar o afeto no centro do desenvolvimento cognitivo e social.

A afetividade ganhou espaço no contexto escolar embasado principalmente nos estudos de Wallon. A função afetiva para Wallon (1989), é primordial para o desempenho de excelência do educador e dos educandos, principalmente para os alunos da educação infantil. $\mathrm{O}$ desenvolvimento afetivo passa por 5 etapas. São elas: a primeira a impulsivo emocional que ocorre no período de 0 a 1 ano, é seguida pela fase do sensório motor e projetivo que acontece no período de 1 a 3 anos. Posteriormente é o estágio denominado de personalismo que acontece de 3 a 6 anos. O quarto estágio do desenvolvimento emocional é o categorial que sucede entre 6 a 11 anos. Por último

\footnotetext{
43. Henri Paul Hyacinthe Wallon, nasceu no ano de 1989 e morreu aos 83 anos em Paris. Médico de formação tornouse também, filósofo e psicólogo. Sua análise voltada para o desenvolvimento humano começou durante a Primeira Guerra Mundial ao acompanhar duas pessoas com dificuldades psicológicas.
}

Educação In Loco, v.01, n. 01, jan.-jun. 2020 
tem-se o estágio da puberdade e adolescência que começa a partir dos 11 anos. (GALVÃO, 1995).

Para que a afetividade aconteça é necessário que a pessoa tenha consciência dos seus valores, de sua disponibilização no espaço. Voltado para o professor ele deve ter a consciência de que se aprendem quando a pessoa sabe o valor que o aprendizado representa para ela (WALLON, 2006).

Na perspectiva da importância da afetividade e da interação no processo ensino aprendizagem da criança, Almeida (2012) ressalta que a afetividade não pode ser confundida com a falta de limites, logo, é imprescindível ações afetivas, mas que também sejam regidas pelas normas disciplinares da escola descritas tanto no Projeto Político pedagógico quanto aquelas feitas com os educandos na sala de aula.

\section{$O$ afeto de acordo com alguns autores}

Apesar da prática do afeto ser ressaltada atualmente, se comparado a outras temáticas da educação, ela merece destaque no cenário educativo, principalmente quando ressaltada por distintos estudiosos: Piaget (1997), Vygostsky (1984) e Wallon (2006). Verificar os saberes destes estudiosos é condição necessária para evidenciar a importância do tema.

Piaget (1997) em sua psicogênese voltada para o empirismo e apriorismo, ressalta que na aprendizagem, até os erros devem ser considerados de acordo com preceitos pedagógicos, pois a criança pode aprender com o próprio erro. Para este autor o afeto consiste na mola propulsora da inteligência, sem o mesmo o aluno não aprende. De acordo com este autor, o afeto promove o desenvolvimento das estruturas cognitivas. A falta do afeto também pode promover o desequilíbrio do indivíduo uma vez que sua estrutura é cognitiva e emocional.

Para Vygotsky (1984) o desenvolvimento acontece mediante as interações sociais da criança com seu meio, para tanto o afeto é condição indispensável para que o aluno aprenda. Defende a teoria sócio interacionista. Para este autor a cultura é essencial no 
desenvolvimento cognitivo do aluno. O desenvolvimento cognitivo vem acompanhado de outras características tais como o afeto que também é essencial na formação da mente da pessoa.

De acordo com Toassa (2009), Vygotsky muito acrescentou sobre a vivência das emoções no processo educativo, pois ele foi capaz de identificar que as emoções principalmente aquelas voltadas para o afeto são fundamentais para que o aluno se desenvolva. $\mathrm{O}$ afeto para ele significa o bom tratamento e o respeito entre quem ensina e quem aprende e acima de tudo a significância que esta relação representa.

Quando a relação professor e aluno é mediada pelo afeto ela é capaz de promover maior confiança, vontade de aprender e determinação tanto por parte do educador, quanto por parte do educando. A vivência do afeto é histórica cultural, à medida que propõem transformações significativas na própria cultura do aluno, através do ensino ele consegue modificar sua cultura e melhorar suas condições de vida, mediado por aquilo que Vygotsky chamou de afeto.

A linguagem é condição necessária entre a pessoa e os processos pelos quais acontecem o desenvolvimento. Mediado pelo afeto o educando tem capacidade de ser autônomo, criativo, sendo este sujeito próprio do seu desenvolvimento. Não é pelo fato de a criança ir à escola que está garantido o aprendizado, ela tem que participar de atividades de classe e extraclasse que garantam o vínculo afetivo entre educando e educador, educando e educando, bem como as demais pessoas envolvidas nesse processo. A partir do momento em que o educador se propõe a esta prática, ele deve conhecer os anseios de seus alunos, suas emoções, dificuldades e facilidades para a partir daí trabalhar com eles, sejam eles crianças ou já mais velhos. (VYGOSTY, 1984).

Wallon (2006), um dos mais recentes teóricos da relação cognição e emoção, ressalta essa teoria psicogenética. Para ele o aluno busca no professor, na escola, nos demais colaboradores condições de aprendizagem que são baseadas pela troca da afetividade, alegria, sentimento, paixão, emoção e confiança. $\mathrm{O}$ professor nesta teoria tem o papel de mediar o conhecimento por 
diferentes estratégias de ensino que envolvam conhecimentos teóricos e práticos.

\section{Prática voltada para o afeto}

Práticas voltadas para a afetividade, ou para as questões do afeto, consistem na predisposição que a pessoa tem para ouvir, para fazer, para interagir de forma espontânea com aqueles que estão ao seu redor.

De acordo com Wallon (2006), a personalidade é constituída de duas funções básicas que são a afetividade e a inteligência, fatores externos e internos aos seres humanos. Para melhor entendimento, o afeto consiste na possibilidade de ser sensível internamente, é a maneira pela qual é proposto e recebido carinho, amor, compreensão e atenção para as pessoas que estão à volta do ser humano.

Já a Inteligência está voltada para os estímulos que vão construir um objeto de conhecimento, por exemplo, para a criança aprender sobre animais ela terá que tocá-los, sentir a cobertura do seu corpo, verificar na prática como se locomovem e assim por diante. Pode-se dizer deste modo que a inteligência é física enquanto que afetividade é sensitiva.

De acordo com Gomes (2013), as implicações do ato afetivo na vida dos escolares vão além da capacidade de aprender. Para esta autora, quando o aluno é afetivamente empoderado ele consegue se colocar no lugar do outro, consegue emitir sua opinião sem medo de ferir, consegue perguntar sobre o que tem dúvida.

Outra questão importante é que quando alunos e professores se mostram afetivamente juntos, a confiança que um passa para outro se torna respeito e o respeito promove mais vontade de aprender, pois quem ensina é considerado uma pessoa de sucesso e quem aprende, uma pessoa cheia de potencial, nesse sentido professor e alunos aprendem juntos. 


\section{Objetivos}

Buscou-se identificar e analisar a importância da afetividade no processo de desenvolvimento da educação infantil. Identificando principais teóricos que falam sobre a importância do afeto como objeto de aprendizagem e como os professores desenvolvem na prática a afetividade e se esta é reconhecida por eles como um bem necessário ao desenvolvimento dos alunos.

\section{Metodologia}

Este trabalho foi desenvolvido com o intuito de verificar como a temática da afetividade é vivenciada na educação infantil, para isso foi divido em dois momentos. Primeiro foi realizada pesquisa bibliográfica e posteriormente pesquisa de campo. $\mathrm{Na}$ pesquisa bibliográfica foi utilizado as ideias de diferentes autores dos quais se destaca Wallon $(1968,1975,1995)$ que apresenta em seus ideais sua teoria psicogenética. Também mereceram destaque na pesquisa bibliográfica Vygotsky (1984, 2003), e Galvão (1995).

Optar pelas pesquisas ressaltadas representou condição necessária para se chegar aos objetivos propostos e assim verificar se a problemática e as hipóteses são verdadeiras ou falsas. Estes tipos de pesquisas, de acordo com Gil (2008), são fundamentais para o estudante que busca trabalhar um tema de forma técnica e prática.

A evolução da tecnologia permite atualmente a pesquisa de dados referente a qualquer temática em sites da internet, inclusive há livros que podem ser baixados e impressos diretamente de endereços eletrônicos, esta realidade fez com que a maioria das obras deste trabalho fosse retirada do Google Acadêmico e do Scielo.

A pesquisa de campo foi realizada mediante a autorização da coordenadora pedagógica da escola. Com a permissão desta profissional foram aplicados 18 questionários no dia 05 de outubro 
de 2019 durante a realização da reunião administrativa da escola pesquisada. No outro dia todos os questionários foram entregues para que se pudesse fazer a análise dos dados e organização dos mesmos em gráficos.

Os dados obtidos durante a pesquisa bibliográfica serviram de organização para a primeira parte do trabalho desde a introdução até o desenvolvimento teórico que discorreu sobre a narração da gênese da afetividade e sua importância. Neste momento também foi discorrido sobre o afeto de acordo com alguns autores bem como a prática do afeto mediada pela relação entre o educando e o educador.

Para melhor entendimento do tema da afetividade no processo de desenvolvimento da criança, foi realizado um paralelo entre os dados obtidos na pesquisa de campo e aqueles obtidos na pesquisa bibliográfica. Para melhor compreensão os dados da pesquisa de campo foram colocados em gráficos que demonstram os resultados dos questionários aplicados.

\section{Resultados e Reflexões}

Os professores sujeitos deste estudo trabalham em uma escola pública da cidade de Vazante. Atuam como regentes e monitores de classe. A referida escola fica localizada no meio urbano, possui 37 funcionários e atende crianças de 0 a 6 anos de idade.

Mediante os questionários aplicados verificou-se que todos os sujeitos são do sexo feminino. Esse fato acontece porque de acordo com Unesco (2004) o perfil de professores da educação infantil demonstra que aqueles que mais se interessam pela escolarização de 0 a 6 anos são as pessoas do sexo feminino.

Com o intuito de verificar a idade dos sujeitos foi perguntada qual a idade dos mesmos. Os dados obtidos com estão descritos no gráfico 1 . 


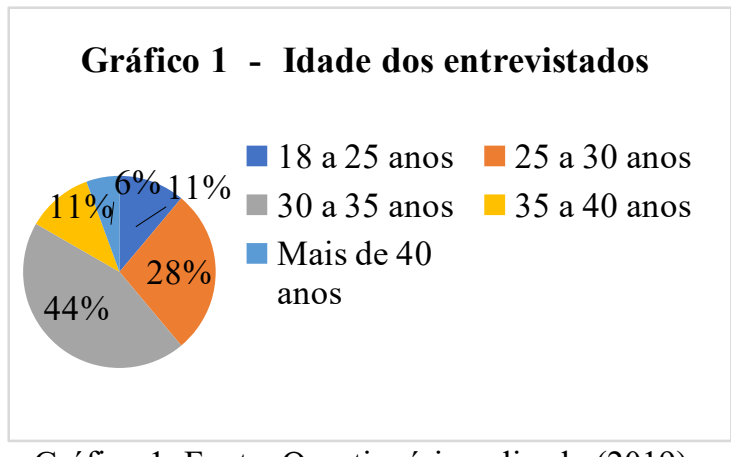

Gráfico 1: Fonte: Questionário aplicado (2019).

Alusivo a idade dos entrevistados, uma educadora possui mais de 40 anos, o que corresponde a 6\% dos entrevistados; outros dois educadores tem idade entre 18 a 25 anos, que corresponde a 11\%; mais dois educadores com idade entre 35 a 40 anos, o que corresponde a 11\%; Outros cinco educadores possuem idade de 25 a 30 anos, e a maioria, 8 professores, o que corresponde a $40 \%$ possui idade entre 30 a 35 anos.

Reconhecer a idade dos sujeitos permite reconhecer, por exemplo, se estes podem ter recebido em sua formação a temática da afetividade, pois esta temática voltada para a efetivação do desenvolvimento é relativamente nova no cenário educativo (ALMEIDA, 2012).

Você concorda que o professor através do afeto promove melhores resultados no desenvolvimento da criança? Os dados obtidos estão descritos no Gráfico 2.

Gráfico 2 - Importância do afeto para aprendizagem

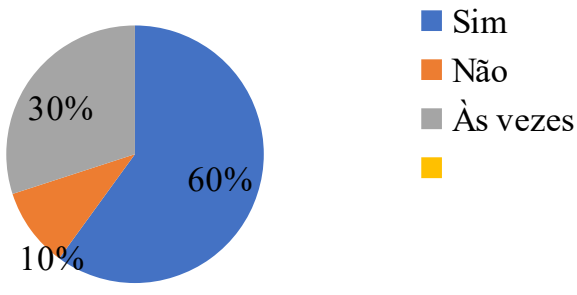


Gráfico 2: Fonte: Questionário aplicado (2019).

Referente a importância do afeto no processo de aprendizagem dos alunos 10 professoras, o que corresponde a $60 \%$ dos entrevistados disseram que sim. Isso é fator positivo, porque como diria Wallon (2006), a criança se desenvolve de forma afetiva, pois todas as áreas do conhecimento estão interligadas. Para que exista desenvolvimento da área cognitiva, psicológica e social por exemplo, o educando deve gostar da escola, do professor, dos colegas, ou seja há uma troca de relações que promove o desenvolvimento escolar e não escolar de forma global.

Se o professor conseguir colocar-se ao lado da criança de maneira educada, amável e respeitosa, sua prática educativa de acordo com Tardiff (2002), promoverá de forma necessária o incremento nos resultados do desenvolvimento da criança.

De acordo com 6 professoras, o que corresponde a 30\% das pessoas entrevistadas, às vezes o afeto promove melhores resultados no desenvolvimento da criança. Isso porque como diria Toassa (2009), o afeto não pode ser confundido com excesso de mimo. Prontamente, a afetividade deve ser vivenciada de maneira dosada, pois o excesso da mesma pode produzir dependência do adulto, principalmente quando for para realizar uma ação que deve expor sua opinião.

Para duas professoras, o que corresponde a $10 \%$, o afeto não promove melhores resultados no desenvolvimento da criança. Estas respostas mostram claramente que estes educadores não conhecem os benefícios que o ensino mediado pelo afeto proporciona aos seus alunos.

O afeto é condição indispensável para o desenvolvimento infantil porque promove vários benefícios. Deste modo foi perguntado: "Você sabe os benefícios da afetividade para a Educação In Loco, v.01, n. 01, jan.-jun. 2020 
criança?". Nesta parte os entrevistados poderiam marcar mais de uma questão. As respostas encontram-se descritas no gráfico 3.

Gráfico

3: Fonte: Gráfico 3 - Benfefíios a afetividades para as crianças

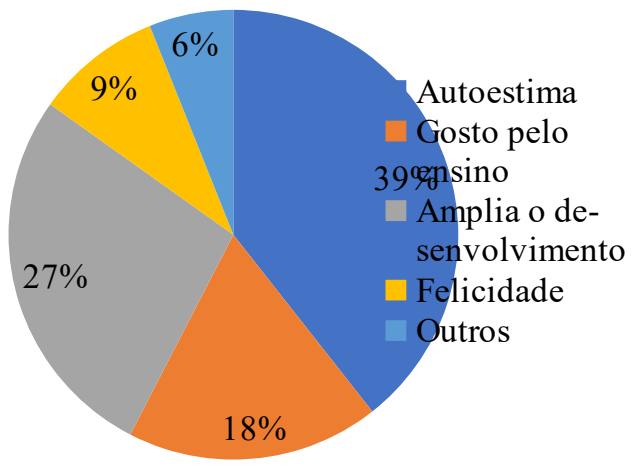

Questionário aplicado (2019).

De acordo com o gráfico, $6 \%$ das respostas ressaltaram o quesito "outros", demonstrando que o trabalho com a afetividade é importante porque promove ao educando, tanto no âmbito da escola, quanto na esfera social a segurança ao resolver conflitos e emitir opiniões.

A afetividade é importante porque promove felicidade, foi citada por $9 \%$ dos entrevistados.

O gosto pelo estudo, consiste na importância da afetividade para $18 \%$ dos entrevistados.

A maioria dos entrevistados, o que corresponde a $40 \%$, ressaltou que os benefícios do trabalho com a afetividade são importantes porque promove a autoestima. Tardiff (2002), ressalta que muitas vezes há uma dicotomia entre os conteúdos que devem ser trabalhados na educação infantil e a maneira pela qual estes serão desenvolvidos de forma prática e prazerosa. De um lado há os educadores tradicionais que tendem a defender um ensino conteudista, baseado na repetição mesmo que seja de forma lúdica. De outro encontram-se educadores que privilegiam a interdisciplinaridade no desenvolvimento escolar infantil reforçando competências e habilidades em prol de assimilação de conteúdo. 
Gráfico 4 - O conteúdo é mais importante que a afetividade

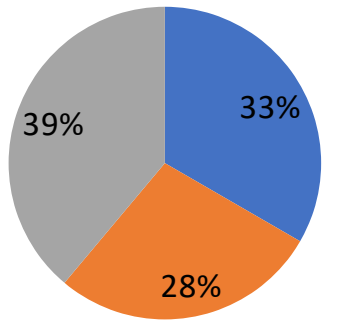

Desta maneira com o intuito de verificar se os professores deste estudo são mais conteudistas ou se estes reconhecem a necessidade da interdisciplinaridade do trabalho com as questões afetivas, foi perguntado: "Você concorda que o ensino infantil tem muito conteúdo, logo é desnecessário o trabalho com as questões afetivas? Os dados obtidos encontram-se no gráfico 4.

Gráfico 4: Fonte: Questionário aplicado (2019).

De acordo com o gráfico 4, cinco pessoas o que corresponde a $28 \%$ não concordam que é desnecessário o trabalho com as questões afetivas em prol de conteúdo.

Seis pessoas, o que corresponde a 33\%, acham desnecessário o trabalho pedagógico voltado para a afetividade. Este fato ocorreu, conforme descreve Gomes (2013), porque muitas vezes o educador, como não entende o processo da educação mediada pelo afeto, ou seja, baseado na teoria psicogenética, acaba achando esta temática desnecessária. Outra questão é que muitos ainda enxergam o afeto desvinculado de outras práticas, como por exemplo de metodologias de ensino, que trabalham com diversos temas, encaixando o afeto de maneira que o próprio conteúdo, competências e habilidades sejam assim melhor assimiladas.

O conteúdo é mais importante do que a afetividade em partes, foi a resposta de sete pessoas, o que corresponde a 39\%. De acordo com Snyders (1999), o conteúdo e a afetividade são temáticas distintas, mas que se completam no decorrer do processo de desenvolvimento infantil. Não tem como o aluno desenvolver apenas por meios afetivos ou apenas pela exposição de conteúdo, ambos são necessários. O que vai prevalecer neste contexto é como o professor conduz tanto as práticas afetivas de relação de troca, quanto ele 
promove as metodologias e as práticas voltadas para diversos assuntos, temas e conteúdos próprios aos estudantes.

Já foi verificado a importância do afeto, assim é interessante analisar quais as principais dificuldades enfrentadas pelos sujeitos no que se refere a vivência de práticas afetivas na sala de aula. $\mathrm{O}$ gráfico 5 demonstra as respostas obtidas. Aqui também o professor poderia marcar mais de uma questão.

\section{Gráfico 5 - Dificuldades na vivência da teoria psicogenética}

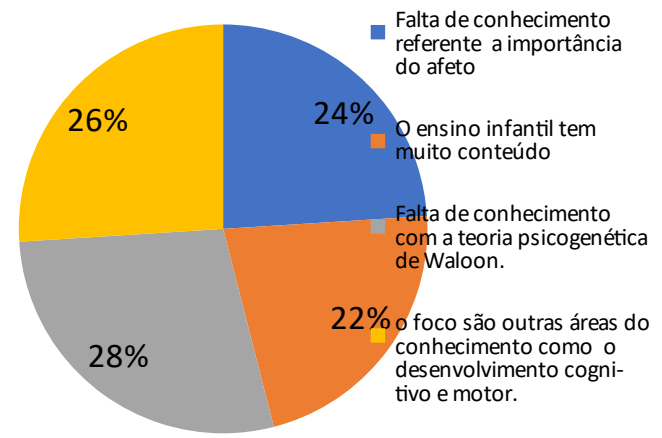

Gráfico 3: Fonte: Questionário aplicado (2019).

Dificuldade na vivência da teoria psicogenética porque a educação infantil possui muito conteúdo foi citada por $22 \%$ dos entrevistados.

Falta de conhecimento referente a importância do afeto foi citado por $24 \%$ dos entrevistados como um dos motivos de não se vivenciar a atividades voltadas para a teoria psicogenética de Wallon.

Outros 26\% relataram que o foco na educação infantil são outras áreas do conhecimento como o desenvolvimento cognitivo e motor. 
Os demais entrevistados ressaltaram que falta de conhecimento com a teoria psicogenética de Wallon faz que os educadores não trabalhem com a questão do desenvolvimento infantil escolar mediado pela afetividade

\section{Considerações Finais}

$\mathrm{O}$ afeto na educação infantil deve ser vivenciado de maneira que a criança potencialize seu desenvolvimento. Para isso é necessário que o educador crie vínculos de respeito, para que as crianças saibam que podem confiar naquele que ensina. Outra questão é que quando a criança gosta do educador fica mais fácil dela gostar daquilo que ele ensina.

Mediante a problemática levantada, foi constatado que apesar da necessidade de se desenvolver emocionalmente ainda há educadores que conduzem sua prática baseada no tradicionalismo, em que o que vale são os conteúdos e não dão a devida importância para a afetividade da criança pelo fato de não reconhecerem as vantagens promovida pelo afeto. Há ainda aqueles que consideram a afetividade como uma dimensão relevante que deve ser vivenciada como as outras dimensões.

\section{Referências bibliográficas}

ALMEIDA, Ana Rita Silva. A emoção na sala da aula. Ed. Papirus, Campinas, SP, 2012.

GALVÃO, Isabel. Henri Wallon: uma concepção dialética do desenvolvimento infantil. Petrópolis, RJ: Vozes, 1995.

GIL, Antônio Carlos. Como elaborar projetos de pesquisa. 4. ed. São Paulo: Atlas, 2008.

GOMES. O lugar do afetivo no desenvolvimento da criança: Implicações educacionais. Psicologia em Estudo, Maringá, v. 18, n. 3 , p. 509-518, jul./set. 2013 Disponível em < http://www.scielo.br/pdf/pe/v18n3/v18n3a11 > Acesso 12 de outubro de 2019. 
SNYDERS, G. Em que sentido podemos falar atualmente de uma pedagogia Walloniana? Enfance, n. 5. 1979.

PIAGET, Jean, Seis estudos de psicologia. Ed Forense Universitária, Rio de Janeiro, 1997.

Organização das Nações Unidas para a educação, a ciência e a cultura; $O$ perfil dos professores brasileiros: o que fazem, o que pensam, o que almejam. São Paulo: Moderna, 2004.

TARDIF, M.Saberes docentes e formação profissional. Petrópolis, RJ, Vozes. 2002.

TOASSA, G. Emoções e vivências em Vigotski: investigação para uma perspectiva histórico-cultural. Tese de doutorado, Instituto de Psicologia, Universidade de São Paulo, São Paulo. (2009.

VYGOTSKY, L. S. A formação social da mente. São Paulo: Martins Fontes, 1984.

VYGOTSKY, L. S. O desenvolvimento psicológico na infância. São Paulo: Martins Fontes. 2003.

WALLON, Henry. O desenvolvimento cognitivo da criança a partir da emoção. Revista Didática Sistêmica, vol.4, julho dezembro de 2006. 